\title{
BREVE. COMENTÁRIO SOBRE A PATOGENIA DA CISTICERCOSE ESPINHAL
}

\author{
A. SPERLESCU*- R. J. BALBO * - S. L. ROSSITTI***
}

\begin{abstract}
RESUMO - A hipótese de que embrióes cisticercóticos possam alcançar os espaços subaracnóidcos espinhais por migraçăo descendente a partir de espaços intracranianos previamente infestados não é compatível ao acometimento leptomeníngeo espinhal primário, que observamos em duas pacientes. E sugerido que nesses casos os embriōes invadem o sistema nervoso central através do fluxo sangüíneo retrógrado pelo plexo venoso vertebral interno e veias intervertebrais, e que o compartimento intracraniano do líqüido cefalorraqueano possa ser secundariamente invadido pelos cisticercos.
\end{abstract}

Brief commonts on the pathogenesis of spinal cysticercosis.

SUMMARY - - The sDina? forms of neurucysticercosis are rather rare, The more common presentation is the leptomeningeal form. We have reported two patients with an exclusively spinal involvement verified through surgery. The current theory of downward migration of the parasites from the cerebral to the spinal subarachnoid space cannot expluin nrimary spinal forms, and it is suggested that retrograde flow through the epidural vertebral veins provides an alternative route.

A cisticercose espinhal é relativamente rara, sendo a forma leptomeníngea sua apresentação mais comum. A concomitância de acometimento encefálico, a baixa freqüência de exame necroscópico sistemático do canal raqueano e a confusão diagnóstica com outras formas de acometimento mielorradicular subagudo ou crônico são Fatores que devem contribuir para a baixa incidência relatada da cisticercose espinhal. Em conseqüência, a experiência clínica de cada grupo de pesquisadores é restrita a casos isolados ou a pequenas séries; sua patogenia é insuficientemente conhecida e, acerca dela, são feitas conjecturas de difícil verificação. Cada novo relato pode trazer importante contribuição ao tema.

Tendo em vista tais ponderaçōes, relatamos recentemente a experiência de nossa clínica 12. Foram revistos os prontuários de 205 pacientes internados de 1961 a 1987 com o diagnóstico de neurocisticercose, dos quais três apresentavam acometimento espinhal (forma leptomeningea) verificado em cirurgia, correspondendo a $1,4 \%$ da série. Não temos observado qualquer caso de cisticerco intramedular ou epidural. Os três pacientes eram do sexo feminino, adultas e caucasianas. Apresentavam quadro clínico de compressão mielorradicular de variada intensidade. Uma das pacientes apresentava cisticercose generalizada e já era acompanhada há 5 anos por apresentar epilepsia. As outras duas não tinham antecedente mórbido relevante e não apresentavam sinais de acometimento encefálico, sendo nelas a forma espinhal presumivelmente primária, observaçāo esta fundamental para a análise crítica da patogenia da

Trabalho do Departamento de Neuro-Psiquiatria da Faculdade de Ciências Médicas da Pontificia Universidade Católica de Campinas (PUCCAMP) e do Departamento de Neurologia e Neurocirurgia do Hospital Vera Cruz, Campinas: *Professor Assistente; ** Professor Adjunto; *** Médico Residente. 
cisticercose espinhal leptomeníngea e, indiretamente, da cisticercose racemosa elu geral. A observação clínica, exames complementares relevantes, tratamento cirúrgico e seguimento dessas duas pacientes são sumariados a seguir.

\section{CASUISTIC.}

Caso 1 - SMCB (HVC 545-81), paciente do sexo feminino, com 28 anos, caucasiana, internada em 1975 com queixa de dor toracolombar, fraqueza nos membros inferiores $e$ incontinência vesical, sintomas estes progressivos há um ano. Esta pacierıte nos foi encaminhada de outra clínica, após investigação inicial e lamincctomia exploratória, com fístula do líquaido cefalorraqueano (LCR) pela ferida cirúrgica. Sem outros antecedentes mórbidos relevantes. Exame neurológico - alerta e orientada, sem disfasias, boa memória e atençăo; naraparesia crural de predominio distal e sinais piramidais; leve espasticidade em membros inferivres; sem amjotrofias; mialgia difusa; sem alterações sensitivas bem definidas; sinal de Lasègue bilateral e cruzado a 40 graus; exame dos nervos cranianos e fundoscopia normais. Mielografía lombar (realizada em outra clínica) - múltiplas falhas de enchimento, de aspecto cistico, ao nivel do cone medular e cauda equina. LCR lombar (colnido por ocasião da mielografia) -- aspecto opalescente, 32 células $/ \mathrm{mm}:$ (2\% de cosinófilos), proteinas totais $53 \mathrm{mg} \%$, reação de Weinberg positiva; provas manométricas para bloqueio, normais. Pneumencefalograma - normal, Eletrencefalograma (EEG) - normal, Operação - laminectomia de $\mathrm{T}_{12}$ a $\mathrm{L}_{2}$, com conservacão da superfície articular, encontrando-se cisticercos racemosos, em grande quantidade, obstruindo o espaço subaracnóideo, aracnóide espessada e opalescente, aderéncias fibrosas em torno do cone medular; máxima evacuação dos cisticercos foi obtida por lavagen do espaço subaracnóideo com solução salina. Evolução - No pós-operatório imediato a paciente referiu melhora importante do quadro álgido radicular \&, no seguimento, apresentou Ienta recuperaçăo da força motora e do controle vesical, permanecendo leve espasticidade nos membros inferiores após dois meses. No ano que se seguiu desenvolveu a forma hipertensiva da neurocisticercose, necessitando de derivaçāo do LCR. Evoluiu com frequientes reexacerbaçōes dos sintomas de hipertensāo intracraniana, sendo necessárias diversas revisões do sistema de derivação ventrículo-peritoneal. óbito após 5 anos.

Caso 2 - EZM (HVC 203-87), paciente do sexo feminino, com 54 anos, caucasianu, internađa em 1987 com queixa de lumbago crônico e irradiação dolorosa para a coxa esquerda há um ano. Exame neurológico e EEG dentro dos limites da normalidade. Mielografia e mielotomografia computadorizada lombar — múltiplas falhas de enchimento, arredondadas, na cauda eqüina. LCR Iombar (colhido por ocasião da mielografia) - límpido e incolor, 24 células $/ \mathrm{mm} 3 \quad(100 \%$ de linfomononucleares), proteinas totais $38 \mathrm{mg} \%$, reação de Weinberg negativa; provas manométricas para bloqueio, normais. Operacăo - laminectomia de $L_{3}$ a $L_{5}$, com preservação da superfície articular; cisticercos racemosos, em grande quantidade e obstruindo o espaço subaracnóideo foram encontrados, tendo sido removidos por lavagem com solução salina; nảo havia sinais de aracnoidite. Evolução - Melhora importante da dor irradiada fó referida no pós-operatório imediato; com a volta às atividades rotineiras voltou a apresentar lumbago, de menor intensidade. obito após 4 meses, por meningoencefalite por E. coli, de curso lento e tumultuado. Por ocasião do inicio do quadro infeccioso foi realizada tomografia computadorizada do encéfalo, na qual não se encontraram lesōes atribuíveis a neurocisticercose.

\section{COMENTARIOS}

E nosso intento tecer breves considerações sobre a patogenia da cisticercose espinhal. É em geral aceito que embriões liberados dos ovos da Taenia solium, ingeridos pelo hospedeiro intermediário, penetram ativamente a mucosa do tracto gastro-intestinal e ganham acesso à circulação venosa, com ou sem passagem pelo sistema porta-hepático 8 . A passagem dos embriões pela circulação venosa abdominal é demonstrada pelo encontro (se bem que raro) de cisticercos hepáticos em necrópsias 8 . A passagem pelo sistema linfático e, daí, para o sistema cava também é proposto 13 . Os embriões passariam pela circulação pulmonar, disseminando-se como êmbolos pelo organismo através da circulação arterial, em especial para o cérebro, músculos e olhos, neles desenvolvendo-se cisticercos 8,13 . E geraimente aceito que, no sistema nervoso, os embriões desenvolver-se-iam em Cysticercus cellalosae quando no interior do parênquima nervoso e, em Cysticercus racemosus, quando no espaço do LCR. As varjaçōes anatômicas do arco aórtico favoreceriam a passagem dos embriões seja para 
a artéria carótida (favorecendo a forma intraparenquimatosa), seja para a artéria vertebral (favorecendo a forma racemosa basal); a disposição clássica do arco aórtico favoreceria a forma mista 13 .

$\mathrm{Na}$ cisticercose intramedular, propóe-se que o parasito possa instalar-se por disseminação hematogênica (arterial)4,10, ou por migração ventriculo-ependimária 4. Queiroz et al.10 analisaram criticamente a patogenia da cisticercose intramedular, com base em 16 casos coletados da literatura e um caso de sua experiência pessoal. A distribuição topográfica dos cisticercos (19 lesões assim distribuidas: 5 cervicais, 12 torácicas e 2 lombares) foi estatisticamente proporcional ao fluxo sangüíneo de cada região medular, o que favorece a hipótese da embolização arterial das larvas. A raridade da forma intramedular torna-se, assim, explicável pelo baixo fluxo sangüineo medular (cerca de 100 vezes menor que o encefálico), pela rede arterial de pequenos vasos sob baixa pressão e, ainda, pelas peculiaridades da medula, cuja riqueza em fibras gliais dificultaria a instalaçăo dos parasitos. Os mesmos autores consideraram plausivel a hipótese de migração ventriculo-ependimária, mas não encontraram evidências que a favoreçam.

$\mathrm{Na}$ forma extramedular leptomeningea (racemosa), postula-se a migração das larvas do espaço subaracnóideo intracraniano (que seria invadido através da artéria vertebral) para o espinhal 13, sendo essa forma de observação mais freqüente na localização cervical que na dorsal ou lombar 4,11,13. O embrião tem diâmetro de cerca de 20 micra 6. Parece-nos que um êmbolo dessa proporção, em meio a corrente sangüinea arterial, ao atingir a artéria vertebral deva prosseguir rapidamente pela artéria basilar e alcançar o território da artéria cerebral posterior ou, menos provavelmente, alcançar algum ramo diencefálico da artéria basilar, dado ser pouco provável que um êmbolo de qualquer natureza passe para os ramos penetrantes da ponte. Ademais, essa teoria não é compativel ao acometimento espinhal leptomeníngeo primário que observamos em nossas duas pacientes. A cisticercose espinhal primária, por vezes evoluindo com acometimento encefálico à distância ou com o aparecimento de cisticercos racemosos basais, foi relatada em outras séries $3,4,5,11$.

Há três décadas, Isamat de la Riva 6 observou que cisticercos racemosos podem abandonar suas localizaçóes primárias, alcançando pontos distantes do lago do LCR por movimentos ativos amebóides, demonstráveis in vitro. $O$ estudo minucioso de seu material, apesar de na época não ter observado qualquer caso de cisticercose espinhal pura, o levou a supor que 'possivelmente nas formas de cisticerco racemoso, a invasão primária do sistema nervoso central se faça ao nivel dos espaços subaracnóideos espinhais'. Ao considerarmos o trajeto percorrido pelo embrião da mucosa do tracto gastro-intestinal ao espaço subaracnóideo espinhal, descartamos de início a via linfática e a propagaçāo por continuidade. A via hematogênica arterial é responsável pela forma intramedular da cisticercose espinhal, sendo improvável que o embrião possa "emergir" do tecido medular para o espaço do LCR. Passamos então a estudar a possibilidade da via hematogênica venosa, a exemplo do que é aceito na esquistossomose medular.

As veias da coluna vertebral constituem sistema paralelo ao sistema cava principal (Fig. 1). O plexo venoso vertebral interno estende-se do cóccix ao forame magno; seus vasos são irregulares, de paredes finas e mergulhados na gordura peridural, o que torna sua dissecção particularmente difícil 9 . Estudos radiográficos em cadáveres e, também em animais vivos, demonstraram que as veias do plexo venoso vertebral interno são desprovidas de válvulas e comunicam-se com as veias vertebrais, intercostais, lombares e sacrais laterais através das veias intervertebrais, principalmente 1,2. Sendo desprovidas de válvulas, essas veias podem conduzir o sangue em qualquer direção e, a despeito de suas paredes finas e delicadas, são capazes de receber grande volume de sangue sem desenvolver varicosidades, funcionalmente sendo um reservatório sangüíneo 9 . Quando a pressão intratorácica e intra-abdominal aumenta, o sangue pode fluir pelo sistema vertebral ao invés de pelo sistema cava, dirigindo-se das vísceras para as veiás peridurais. A congestão passiva da medula espinhal, nessas ocasiões, é prevenida por pequenas válvulas nos ramos radiculares, responsáveis pela drenagem venosa medular ${ }^{9}$. Desse modo é possivel a disseminação espinhal de neoplasias ou de processos inflamatórios oriundos das cavidades torácica, abdominal e pélvica, bem como a disseminação para regióes anatômicas associadas a conexōes năo valvuladas do plexo 1,2 . 
S!̣gerimos, assim, que na neurocisticercose o embrião possa alcançar o espaço subaracnóideo espintal pelas veias peridurais, desenvolvendo-se em sua forma racemosa e originando, deste modo, formas clínicas primariamente espinhais leptomeningeas. Localizados no espaço subaracnóideo espinhal, os cisticercos provocariam no hospedeiro respostas imumo-alérgicas locais e à distância evoluindo, do ponto de vista imunológico, de modo crônico repetitivo 7. Podem, ainda, ascender ao espaço subaracnóideo intracraniano átravés do forame magno, invadindo as cisternas da base e 0 sistema ventricular 6 . A raridade da cisticercose epidural poderia ser devida à pouca afinidade do parasita por essa localização, bem como poderia ser explicada pela pequena freqüência em que é feito o exame necroscópico sistemático do canal raqueano.

Conclusões - 1. Na cisticercose intramedular é provável que o embriāo seja implaritado no tecido medular por embolização arterial. 2. Na cisticercose espinhal leptomeningea (racemosa) é provável que o embrião invada o espaço subaracnóideo espinhal através das conexōes do plexo venoso vertebral interno. 3. A cisticercose racemosa das cisternas da base pode ser secundária a acometimento espinhal primário.

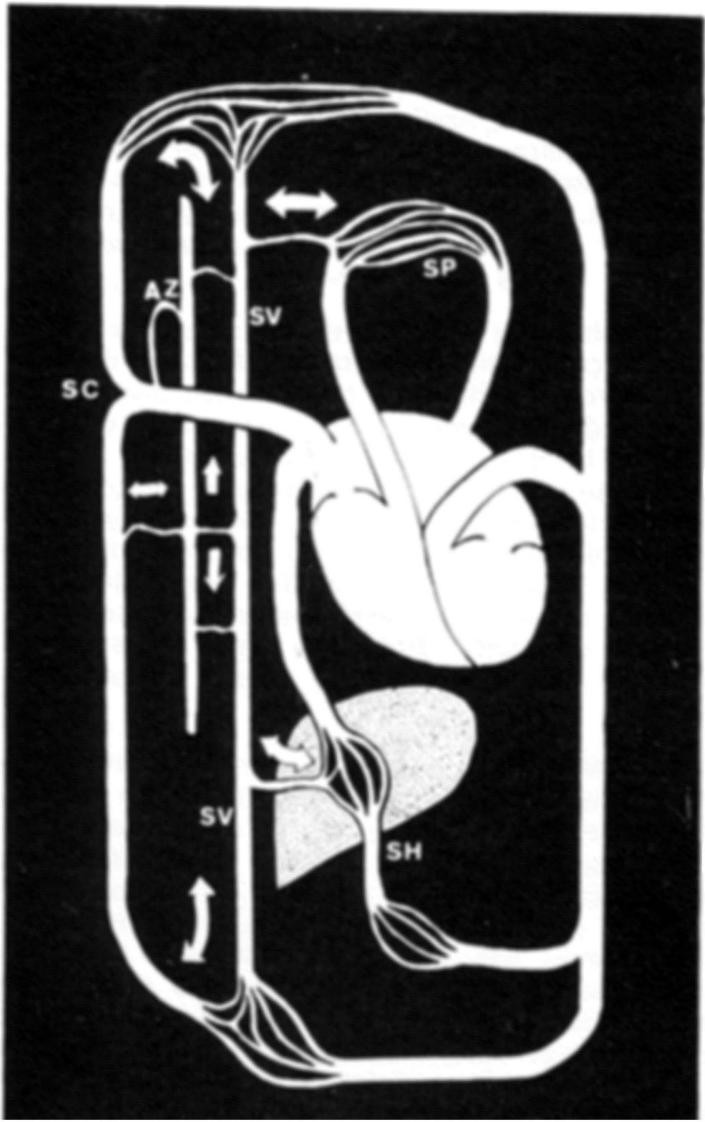

Fig. 1 - Diagrama das conexões do sistema venoso vertebral (SV) com os sistemas cavia (SC), pulmonar (SP) $e$ porta-hepatico (SH), bem como com a veia azigos (AZ). Modificado de Batson(1,2). As setas indicam as constantes mudanças na direção do fluxo sangüineo. 


\section{REFERENCIAS}

1. Batson ov - The function of the vertebral veins and their role in the spread of metastases. Ann Surg 112:138, 1940.

2. Butson ov - The role of the vertebral veins in metastatic processes. Ann Intern Med $16: 38,1942$.

3. Bussone G, La Mantia L, Frediani F, Lamperti E, Salmagyi A, Campi A, Sinatra MG, Boiardi A - Neurocysticercosis: clinical and therapeutic considerations. Review of italian literature. Ital J Neurol Sci 7:525, 1986.

4. Canelas HM, Ricciardi-Cruz O, Escalante OAD - Cysticercosis of the nervulis systen: less frequent clinical forms. III. Spinal cord fornis. Arq Neuro-Psiquiat (Sāo Paulo) $21: 77,1963$.

5. Carydakis C, Baulac M, Laplane D, Schuller E, Philippon J - Cysticercuse spinale pure: note sur le liquide céphalo-rachidien. Rev Neurol 140:590, 1984.

6. Isamat de la Riva $\boldsymbol{F}$ - Cisticercosis Cerebral. Vergara, Barcelona, 1957, pg 29.

7. Livramento JA, Machado LR, Spina-França A - Sinalizaçâo do liquido cefalurrarutuedno em doenças inflamatórias crônicas do sistenı nervoso central. Arq Neuro-Psiquiat (São Paulo) 44:351, 1986.

8. Monteiro-Salles FJ - Cisticercose Cexebral. Tese. São Paulo, 1934.

9. Parke WW - Applitd anatomy of the spine. In Rothman RH, Simeone FA (eds): The Spine. Saunders, Philadelphia, 1975, vol 1, pg 19.

10. Queiroz LS, Pellegrini A Filho, Callegaro D, Faria LL - Intramedullary cysticercosis: case report, literature review and comments on pathogenesis. $J$ Neurol Sci 26:61, 1975.

11. Rocea ED, Neira B - Cisticercosis del raquis, Rev Neuro-Psiquiat (Lima) 42:96, 1979.

12. Sperlescu A, Balbo RJ, Rossitti SL - Cisticercose espinhal: a propósito de três casos. Simpósio Neurocisticercose '88: Controvêrsias e Perspectivas. São Paulo, março de 1988.

13. Trelles JO, Trelles L - Cysticercosis of the nervous system. In Vinken PJ. Bruyn GW (eds): Handbook of Clinical Neurology. North-Holland, Amsterdan, 1978, vol 35. py 291. 